\title{
O ESPECISMO COMO ARGUMENTO FILOSÓFICO DA NÃO ACEITAÇÃO DO ANIMAL COMO SUJEITO DE DIREITOS
}

\section{SPECIESISM AS PHILOSOPHICAL ARGUMENT OF NON-ANIMAL RIGHTS AS ACCEPTANCE OF SUBJECT}

\section{RESUMO}

\author{
Renato Carlos Cruz Meneses ${ }^{1}$ \\ Tagore Trajano de Almeida Silva ${ }^{2}$
}

O presente artigo propõe-se a abordar os argumentos filosóficos que se opõem a aceitação do animal não-humano como sujeito de direito, fazendo uma abordagem na filosofia antropológica e propondo-se a transcender o homocentrismo, para demonstrar a necessidade de mudança de paradigma numa perspectiva de dignidade do animal não-humano. Dessa forma, propõe-se afastar o discurso do especismo, como forma de desconsideração moral engendrada pelos humanos em desfavor dos não-humanos, para adoção de uma nova linguagem que reconhece homens e animais com características comuns, ainda que em graus diferentes, para admitir aos animais a condição de sujeitos de direitos por serem detentores de valor intrínseco.

Palavras chave: Especismo; Animal; Dignidade.

\section{ABSTRACT}

This article aims to address the philosophical arguments against the acceptance of non- human animal as a subject of law, making an anthropological approach and proposing demonstrate the need for paradigm shift in dignity perspective of non- human animal. Thus, it is proposed away speciesism speech as a way to disregard moral engineered by humans to the detriment of nonhuman, for the adoption of a new language that recognizes men and animals with common characteristics, although in different degrees, to admit animals the subjects of rights condition for being intrinsic value holders.

Keywords: Speciesism; Animal; Dignity

\footnotetext{
${ }^{1}$ Mestrando em Direitos Humanos (PPGD/Universidade Tiradentes - Unit). Especialista em Direito Penal e Processual Penal pela Universidade Tiradentes - UNIT. Professor do Curso de Direito da Universidade Tiradentes Unit. Advogado OAB/SE 2.455. Sergipe (Brasil). E-mail: cruzadvocacia@ gmail.com

2 Pós-doutor em Direito pela Pace Law School, New York/USA. Doutor e Mestre em Direito Público pela Universidade Federal da Bahia (UFBA) com estágio sanduíche como Visiting Scholar na Michigan State University (MSU/USA). Pesquisador Visitante da University of Science and Technology of China (USTC/China). Professor Visitante da Pace Law School, Williams College e Lewis \& Clark Law School. Ex-Presidente do Instituto Abolicionista pelos Animais (www.abolicionismoanimal.org.br). Professor Pleno I do Programa de Pós-graduação em Direito da Universidade Tiradentes (Unit/SE). Professor Adjunto I da Universidade Federal da Bahia - Fundação Faculdade de Direito. Professor do II Posgrado Internacional sobre "Derechos de los Animales y Sociedad Ética del Siglo XXI - Facultad de Derecho - UNNE - Corrientes - Argentina. Membro do Núcleo Interdisciplinar de Pesquisa e Extensão em Direitos dos Animais, Meio Ambiente e Pós-humanismo - NIPEDA (www.nipeda.direito.ufba.br). Coordenador Regional do Brazil-American Institute for Law and Environment - BAILE (http://www.law.pace.edu/BAILE). Editor acadêmico do site do Mestrado em Direito e Sociedade da Universidade Autônoma de Barcelona/Espanha (www.derechoanimal.info). Coeditor da Revista Brasileira de Direito Animal (Salvador/BA - ISSN 1809909-2). Membro-fundador da Asociación Latinoamericana de Derecho Ambiental. Advogado. Sergipe (Brasil). E-mail: tagore@ufba.br.
} 


\section{INTRODUÇÃO}

Não raro, somos frequentemente surpreendidos com notícias de maus tratos e tratamento cruéis aos animais não humanos. Poder-se-ia dizer que já existe tratamento penal para as questões e que a discussão encerrar-se-iam com as sanções legais.

Em verdade, a discussão não se limita a aplicação do Código de Iras, pois há ainda enraizado uma falsa ideia de superioridade do humano sobre os demais seres. Temse a concepção de que o meio ambiente, como o todo, está a serviço dos interesses do animal racional, ou seja, não dispõe a natureza de valor intrínseco, mas apenas extrínseco de acordo a finalidade proposta pelo homem.

Nessa perspectiva de discussão do antropocentrismo como manifestação do narcisismo exacerbado do humano é que o presente artigo se propõe a discutir a filosofia homocêntrica como expressão do especismo ${ }^{3}$, para a não aceitação do animal como sujeito de direitos.

A discussão ganha mais interesse, porque em terras nacionais há grande discussão sobre a temática de um direito animal, notadamente em perspectivas diversas. A título de exemplo, divulgaram amplamente, através das redes sociais em 19.05.16, a existência de um processo que tramita no Estado de Santa Catarina, mais especificamente na $7^{\mathrm{a}}$ Vara Cível da Comarca de Joinville, onde o magistrado Leandro Katscharowski Aguiar entendeu que o cão não era um objeto, mas um ser senciente e dotado de certa consciência. Logo, entendeu ele que essa questão deveria ser discutida na Vara de Família (Juiz...,2016).

Assim, pretende-se discutir neste artigo: 1) como a filosofia antropocêntrica interferiu na realidade humana, em especial com os textos de Aristóteles, Tomás de Aquino, Descartes e Kant, sendo objeto de contestação pela proposta de Direito Animal de Henry S. Salt e das correntes filosóficas de Peter Singer e Tom Regan; 2) como a dignidade pode ir além do significado humano, perpassando para uma proposta de dignidade para os demais animais.

Desse modo, trataremos da filosofia antropocêntrica como manifestação do narcisismo humano e após, faremos uma abordagem propondo uma mudança de paradigma, para reconhecer a dignidade animal e seu corolário.

\footnotetext{
${ }^{3}$ Especismo - termo criado por Richard D. Ryder, que para Sônia Felipe indica uma forma de desconsideração moral, ora praticada pelos humanos em face dos interesses dos animais, com a argumentação de que os interesses dos nãohumanos não detêm o mesmo peso moral dos humanos.
} 


\section{FILOSOFIA ANTROPOCÊNTRICA: SUPERANDO O NARCISISMO HUMANO}

A concepção da existência de um Direito Animal tem se apresentado não só na academia, mas,também, no senso comum,como uma temática de difícil aceitação. Notadamente, por uma ideia intrínseca que somente o humano poderia ser sujeito de direitos e que o não humano seria apenas objeto de uma tutela ambiental, partindo-se de uma noção exclusivamente de preservação do meio ambiente, retrato típico de uma visão instrumentalista.

Essa visão instrumentalista concebe o animal como coisa, objeto de posse, de valor apenas extrínseco, sobre o qual, de forma individual, pode-se agregar uma maior valorização, especialmente ao não humano doméstico. Assim, o animal, numa visão antropocêntrica, está adstrito ao homem a finalidade que se deseja dar, ou seja, para alimentação, vestuário, entretenimento, conhecimento.

No entanto, esse olhar para o não humano entra em rota de colisão com a teoria do Evolucionismo de Darwin, a qual postulou que a diferença entre aquele e o homem é apenas de grau e não de categoria, logo o humano não ocuparia um local de sobrelevo na ordem natural (Silva, 2012).

Contrariando o postulado evolucionista, a visão ocidental tradicional, a partir do pensamento aristotélico ${ }^{4}$, passou a entender o meio ambiente natural como uma compreensão antropocêntrica, donde a natureza era um bem a ser utilizado a favor do humano e em benefício deste. Dizia o filósofo que havia uma hierarquia natural na natureza, do qual constava no topo a figura humana, nominada de seres racionais, estando abaixo aqueles de menor capacidade de raciocínio a serviço de quem ocupa o topo da pirâmide.

Desse modo, o homem é entendido como o centro do universo, perpassando essa concepção pela modernidade e mantendo-se na contemporaneidade, notadamente em setores de formação tradicional, sedimentando a condição do não humano de

\footnotetext{
${ }^{4}$ Aristóteles (384-322 a. C.) sustentava a ideia de que o Cosmos seria colocado à disposição do homem, como argumenta Danielle Tetü Rodrigues (2011, p. 40) "[...] Na cosmovisão aristotélica, imperava a supremacia do ser humano sobre a Natureza e sobre todos os outros seres, os quais estariam a serviço do homem".
} 
subserviência ao humano. É como que tudo que existe no mundo está à disposição para satisfação e gozo desse dito homem.

Ora, se o homem é o único ser dotado da capacidade de pensar e agir de acordo com o pensamento, de planejar, de criar cultura, riquezas e, por fim, de manipular seu presente e futuro, não se pode conceber que ele se encontra sozinho nesse meio ambiente exclusivamente como sujeito de direitos, mas, também, como parte dele integrante, inserido num contexto em correlação como os demais.

Ora, se o humano tem o direito à vida, à liberdade, dentro de uma concepção ambiental, de igual sorte o não humano também. Assim, pode-se dizer que o animal inserido no contex to de um zoológico como instrumento de entretenimento tem o direito de ser mantido em seu habitat natural de forma livre.

O filósofo australiano Peter Singer (2010, p. 235), já advertia que

[...] A ignorância generalizada quanto à natureza dos não humanos permite àqueles que o tratam cruelmente que se eximam de críticas, afirmando que, afinal, 'eles não são humanos'

Esse argumento, doravante chamado de especismo, transmite a ideia de que o meio natural está à disposição do homem, como mero fornecedor de bem-estar, numa concepção utilitarista de seu desejo, sem querer aprofundar aqui o uso racional ou irracional de um meio ambiente sustentável.

Segundo Aristóteles (2007, p.27), numa visão principiológica racional:

\begin{abstract}
A vida parece ser comum até as próprias plantas, mas estamos, agora, buscando saber o que é peculiar ao homem. Excluamos, pois as atividades de nutrição e crescimento. A seguir, há atividade de percepção, mas dessa também parecem participar o cavalo, o boi e todos os animais. Resta, portanto, a atividade do elemento racional do homem; desta uma parte tem esse princípio racional no sentido de ser obediente a ele, e a outra, no sentido de possui-lo e de pensar.
\end{abstract}

Influenciado pelo pensamento Aristotélico, o Tomás de Aquino, filósofo cristão, também entendia que a natureza estava a serviço do homem, pois acreditava que os seres menos perfeitos estavam a serviços dos seres mais perfeitos.

Nessa visão, difundiu a ideia que não havia pecado usar algo para o fim que fora destinado. Segundo o filósofo, assim como a planta está para o bem dos animais, de igual modo estão os não humanos para os humanos. 
Por tal razão, Tomás de Aquino (2004, p. 222) chegou a afirmar que o sexto o mandamento da bíblia, ou seja, não matarás, não poderia ser imputado ao homem em razão do animal, posto que a natureza deste é servir aquele.

Esse antropocentrismo também é visto no pensamento do filósofo Descartes que atribui aos animais o substantivo de máquinas criadas por Deus, negando, inclusive, a capacidade deles sentirem dor e prazer. Segundo o pensador, não possuem alma imortal, não seriam seres sencientes.

O pensamento Kantiano (Kant, 1964) também sustenta essa visão de finalidade do animal ao bem-estar do homem, quando afirma que: "os animais não são autoconscientes e estão lá apenas como meio para o fim. Esse fim é o homem [...]".

Na obra Direitos Fundamentais e proteção do ambiente, Tiago Fensterseifer (2008, p. 49) traz um esclarecimento sobre o pensamento Kantiano:

\begin{abstract}
A formulação Kantiana coloca a ideia de que o ser humano não pode ser empregado como simples meio (ou seja, objeto) para satisfação de qualquer vontade alheia, mas sempre deve ser tomado como um fim em si mesmo (ou seja, sujeito) em qualquer relação, seja em face do Estado seja em face de particulares. Isso se deve, em grande medida, pelo reconhecimento de um valor intrínseco a cada existência humana.
\end{abstract}

O filósofo alemão reconhece um valor intrínseco a cada humano, partindo da ideia de autonomia, de liberdade, de racionalidade e de autodeterminação inerentes à condição humana. Somente o homem possui dignidade, como ser racional, portanto sujeito de direitos e nessa condição não é um simples meio para satisfação alheia, mas sempre um fim em si mesmo em qualquer relação, seja ela em face de particulares, seja em face do Estado.

Não sem razão que o Estado estabelece um manto ético e jurídico do humano, partindo dessa concepção principiológica de dignidade humana Kantiana, como axioma de todo o ordenamento jurídico. A Constituição federal vigente pátria é um dos exemplos da influência Kantiana, quando estabelece em seu art. $1^{\circ}$, inciso III, como fundamento, a dignidade da pessoa humana.

Entretanto, não pode ser concebível a existência apenas de uma única dignidade, a dignidade humana. Pelo contrário, o animal não humano, contrariando a visão Kantiana, possui também um valor intrínseco, ora positivado na Declaração Universal dos Direitos dos Animais da UNESCO, a despeito de sua natureza ser soft law, quando prevê em seu art. $2^{\circ}$ que todos os animais têm o direito de ser respeitado. 
Essa visão antropocêntrica, que se arrasta na história da humanidade, em especial na Idade Média, onde humano era considerado a imagem e semelhança de Deus, ora criador das máquinas no pensamento de Descartes já abordado, parece ser fruto de um narcisismo humano desmedido.

Há quem sustente que todos os seres possuem graus de narcisismo, porém ao homem parece que esses níveis de tolerância foram ultrapassados, a ponto de não reconhecer a necessidade, desejos e interesses de terceiros. É como se tivesse o bloqueio mental neste sentido (Barlett, 1986).

O escritor Steven J. Barlett, escrevendo sobre o tema Raízes da resistência humana aos direitos dos animais em artigo publicado na Revista Brasileira de Direito Animal (Revista...,2007, p. 41), ilustrou o seu trabalho trazendo um pensamento de um certo autor, que numa manifestação tipicamente narcicística pontuou:

Que se danem os direitos da natureza! Ela os terá tão logo também possua deveres. No momento em que virmos pássaros, insetos e roedores limpando as ruas, doando dinheiro aos necessitados, ou mesmo vigiando nossas crianças no parque, nós então lhes concederemos o direito de votar.

Essa manifestação de superioridade humana, no curso da biografia da humanidade, se volta contra o próprio animal homem. Registra a história da superioridade do homem branco sobre o negro (processo de escravidão), da burguesia sobre o proletariado (na modernidade), de uma suposta raça pura nominada de ariana sobre a judia (nazismo).

O narcisismo parece estar impregnado na espécie humana, promovendo diversas manifestações de traços egoísticos. Sob essa ótica é que se sustenta na visão homocêntrica, que crer que:

\footnotetext{
O mundo foi criado tão somente para o benefício do homem que, por sua vez, ocupa o topo da ordem da criação. Os homens, porque dotados de razão, estão em lugar de destaque na hierarquia natural e, deste modo, podem tiranizar a natureza sem enfrentar qualquer dilema moral.
}

Parece haver uma necessidade para o animal humano de uma autoafirmação da espécie em detrimento das demais. É preciso demarcar terreno, evidenciar a condição de superioridade humana, de posição moral privilegiada que legitime a sua posição de dominador. 
Esse especismo, fruto de um narcisismo entranhado no humano, passar a guardar traços ou semelhanças com uma patologia psicológica. O narcisista, digo doentio, manifesta-se pela necessidade intensa de autoafirmação somada com uma postura de não admissão dos próprios erros, de orgulho e pela rejeição da condição de falibilidade (Steven, 1986). Isso perpassa também a individualidade do ser humano, alcançando grupos, que passam a conceber outros grupos sociais como desprovidos de personalidades, portanto marginalizados ou alijados de um determinado processo de desenvolvimento.

Assim, foi no descobrimento das Américas, onde os descobridores, num sentimento de superioridade humana, passaram a exterminar os habitantes locais, quando não os catequizaram como se fossem moralmente insignificantes.

O professor Steven J. Barlett, tratando do narcisismo numa perspectiva homocêntrica na referida revista de Direito Animal (2007, p.50) citou que

Grupos nacionalistas, cegos pela grandiosidade de seu amor-próprio e pela enorme autoabsorção derivada do narcisismo, são marcados pelo repúdio inconseqüente dos valores de quem não participe de sua comunidade.

Essa visão centrada na autoafirmação permite dizer que a manifestação do homem em relação a outras espécies tem seu fundamento na crença irretocável de que o humano é um ser diferenciado e com destaque dos demais não humanos.

Esse comportamento pode ser relacionado ao autismo, numa visão coletiva, onde o humano estaria acorrentado ao narcisismo. Faz essa pontuação, justamente porque o autista tem ausência de habilidade de promover relações próximas.

Parece, como se diz no jargão popular "forçar a barra", mas não o é, eis que o especismo, que se manifesta como narcisismo exacerbado, e, agora, também assemelhado com traços do autismo, tem sido a causa maior da resistência ao Direito Animal, que propõe o reconhecimento do não humano como sujeito de direitos.

Indo pouco mais além, o narcisismo traz consigo baix a carga empatia, o que justificaria a exploração de outros seres pelo ser humano como se tal fosse uma espécie dominante e a mudança de paradigma não é o seu anseio, uma vez que ancorado na própria auto-imagem e como ocupante do topo da pirâmide num olhar kantiano, hierarquicamente falando. 
Em outro momento de sua contribuição a pré-falada revista de temática animal não humano, o professor Steven J. Barlett (2007, p.55) pontua que

A resposta humana ao sofrimento de outras espécies é governada não só pela sua resposta narcisista em relação a eles, mas também por um certo egoísmo genético.

O professor Barlett (2007, p. 56) chega a comparar o egoísmo humano ao fenômeno biológico do parasitismo, onde se verifica autopreservação a todo custo e às custas do hospedeiro. Assim, ele assemelha o homem a uma espécie de parasitas de várias outras, a qual mantém a sua preservação mediante a exploração de outros seres não humanos.

Afirma o professor (2007, p. 56), que

\footnotetext{
Na espécie humana, o egoísmo genético do parasita tomou a forma de nossa autosuficiência de espécie, de nossa oportunística exploração dos recursos ambientais, e de nosso descaso para com o extermínio de outras espécies.
}

Assim, parece que se impõe como condição cogente a mudança de paradigma, refreando esse egoísmo desmedido, para um pensar altruísta de uma preocupação com o outro (outra espécie), a despeito de limitações no bem-estar, enxergando no não humano valores intrínsecos.

Na obra "Animais em Juízo" (Silva, 2012), partindo das proposições de Richard D. Ryder, Peter Singer, Stanley e Roslind Godlowich, John Harris e Andrew Linzy, pontuou que se deveria transcender o pensamento Kantiano, ora referindo-se a visão antropocêntrica do especismo, propondo

[...] a necessidade de rever criticamente a filosofia moral tradicional e adotar um único princípio para considerar moralmente todos os seres semelhantes atendendo ao que ordena a justiça, ou seja, tratamento igual para os casos semelhantes.

\section{RECONHECIMENTO DA DIGINIDADE DO NÃO HUMANO: UM NOVO MARCO JURÍDICO-CONSTITUCIONAL}


Em recente matéria circulada na internet, um informativo on-line nominado "extra", publicou em sua grade de notícias no dia cinco de setembro do corrente ano, que uma adolescente com a idade de doze anos tinha como prática publicizar nas redes sociais fotos ao lado das suas caças abatidas. Nessa reportagem, por sinal, a jovem caçadora publica, com a arma de caça em punho, a foto de girafa abatida, tendo sido objeto de várias contestações pelas redes sociais (Dignidade..., 2016).

Um fato que chamou bastante atenção nesse episódio, além, é claro, da imagem da girafa morta, fora a manifestação da adolescente, quando questionada sobre a repercussão negativa das imagens nas redes sociais, tendo dito ela, naquela oportunidade que "estou muito chateada que as pessoas valorizam mais a vida de um animal do que de outra pessoa".

Algumas indagações surgem desse fato, dentre elas se os animais abatidos por essa garota não tinham o "direito" de viverem o seu ciclo de vida normal em seu habitat natural? Teriam eles dignidade ou enquanto coisas estariam a serviço da destinação que os humanos possam querer dar?

A expressão dignidade surge do latim "dignitas", que significa honra, virtude, sempre atrelado a condição de humanidade numa abstração intelectual que representa um estado de espírito.

No pensamento clássico e cristão, a dignidade era concebida como uma qualidade própria do homem que o diferencia das demais criaturas (Sarlet, 2006). No entanto, abordando a visão kantiana que transcende a visão social e religiosa do conceito de dignidade, partindo de uma premissa que o humano detém predicados próprios, pontua Feijó (2008, p.129) que

[...] essa dignidade outorga ao ser humano uma liberdade de ação autodeterminada, um agir orientado pelo dever originado a priori da razão. A liberdade seria a consciência moral autônoma que daria a simesma suas leis. O dever se imporia por si mesmo a todo ser racional sem necessidade de justificativa, o que seria o Imperativo Categórico Kantiano.

Para o filósofo Kant, a autonomia de vontade, que se retrata a capacidade de autodeterminasse e agir em conformidade com a representação de determinadas leis, é propriedade específica dos animais racionais, constituindo-se o fundamento da dignidade da natureza humana. Esse pensamento Kantiano é, na contemporaneidade, inspirador de sucessivas cartas magnas dos Estados democráticos de direitos (Sarlet, 2006).

A título ilustrativo, a Constituição Federal de 1988, notadamente influenciada pelo pensamento do filosófico em análise, preconiza no art. $1^{\mathrm{o}}$ inciso III, a dignidade da pessoa humana 
como princípio fundamental legitimador de todo o arcabouço jurídico pátrio. Trata-se da pedra angular, pedra de toque.

Abordando a ideia conceitual, Sarlet diz que dignidade é

\begin{abstract}
(...) a qualidade intrínseca e distintiva reconhecida em cada serhumano que o faz merecedor do mesmo respeito e consideração porparte do Estado e da comunidade, implicando, neste sentido, umcomplexo de direitos e deveres fundamentais que assegurem apessoa tanto contra todo e qualquer ato de cunho degradante edesumano, como venham a lhe garantir as condições existenciaismínimas para uma vida saudável, além de propiciar e promover sua participação ativa e co-responsável nos destinos da própria existênciae da vida em comunhão com os demais seres humanos.
\end{abstract}

Assim, vê-se que a concepção de dignidade está atrelada a um valor intrínseco próprio do ser humano, da sua condição existencial não vista como simples objeto, mas como sujeito nas relações sociais e intersubjetivas. Portanto, uma concepção de dignidade animal não é possível na visão Kantiana pela exacerbada visão antropocêntrica.

O filósofo Tom Regan já alertava da visão exasperada antropocêntrica de Kant, que limitava a ideia de dignidade a condição de humanidade (Silva, 2012).

Assim, impõe-se transcender a visão kantiana e passar analisar o meio ambiente não apenas numa perspectiva da saúde e qualidade de vida do ser humano, mas em virtude de representar um valor em si mesmo. É, em verdade, o reconhecimento de um direito animal.

O escritor Tagore Trajano já propunha (2009, p. 2891) uma mudança na hermenêutica jurídica, para retificar erros nas teorias passadas, efetivamente ancorado nos direitos animais, de que o direito não é uma instituição social destinada para os homens, mas para todos aqueles que são sujeitos de comunicação. Essa nova significação jurídica incluía os animais não-humanos.

A primeira abordagem sobre direito animal tem seu marco histórico na obra Animal Rights (Direitos dos Animais), em 1892, de Henry S. Salt. Para o escritor, a existência de um direito animal não está presa apenas ao sentimento de simpatia e compaixão, mas de direitos básicos, tais como uma liberdade para a vida natural (Silva, 2012).

Para tanto, existem a duas correntes filosóficas que definem o que sejam direitos dos animais. A primeira trata-se do Bem-estar animal, que nega toda manifestação de sofrimento desnecessário ao não humano. O filósofo Peter Singer é um dos defensores dessa minimização do sofrimento.

A segunda é chamada de Abolicionismo animal, que prega a exclusão de toda a forma de uso do animal não humano, por reconhecer a existência de direitos básicos. Tom Regan é defensor dessa doutrina, conforme se vê em sua obra The case for Animal Rights (Silva, 2012). 
Sem aprofundar as questões que envolvem as teorias filosóficas acima citadas e indo além de um discurso de proteção do meio ambiente, impõe-se reconhecer a existência de um direito dos animais. Tal discussão perpassa pela releitura crítica da filosofia moral tradicional, segundo Richard D. Ryder, Peter Singer, Stanley e RosilindGoldowitch, John Harris e Andrew Linzey, para reconhecer, também, dignidade aos animais não humanos, como bem acentua o professor Tagore Trajano (2012, p. 79)

[...] adotar um único princípio para considerar moralmente todos os seres semelhantes, atendendo ao que ordena a justiça, ou seja, tratamento igual para os casos semelhantes.

Neste sentido, a Constituição da Suíça é inovadora ao trazer em seu artigo 24 a expressão “dignidade da criatura”, referindo-se a ideia de respeito, especialmente, no âmbito da legislação sobre engenharia genética.

Essa valoração no aspecto perceptivo de construção de dignidade, no pensamento de Bolssemann, deve o animal humano respeitar o valor intrínseco dos outros seres, fundamentandose na existência de deveres ecológicos com as demais manifestações existenciais (Bosselmann, 2006).

Deve-se, ainda, romper com essa ideia civilista de que o animal não-humano é simples coisa inanimada, um semovente, passível de apropriação, e que, portanto, deve estar adstrito as finalidades que humano possa dar. Pois, os animais são seres dotados de sentimento dolorosos, são sencientes e com grau de raciocínio inferior ao humano, que importará em concessão de direito diferentes, mas não na sua negação em razão do especismo.

Sobre este prisma, Peter Singer pontua que ninguém pretende a concessão do direito de voto ao animal não-humano, mas a igualdade principiológica no plano material com o humano (Singer, 2004).

Por isso, que Tagore Trajano (2012, p. 62) argumentou que

É nesse sentido que logicamente podemos estender este princípio para os demais animais, afirmando que, na relação entre humanos e não-humanos, o fato de nãohumanos pertencerem à outra espécie não nos dá o direito de utilizar o sistema jurídico contra eles.

Arremata, ainda, afirmando (Silva, 2012) 
O princípio da igual consideração de interesses é o princípio básico que fundamenta a defesa de uma forma de igualdade que inclua todos os seres humanos, com todas as diferenças que existem entre eles.

A desigualdade é um elemento presente na história da humanidade. Outrora tínhamos o processo da escravidão, onde o branco era superior ao negro e, portanto, este deveria atender as finalidades daquele. Com o surgimento da modernidade, ocorreu a predominância de uma classe social sobre outra. Não muito distante, houve, também um processo de luta pelo empoderamento da mulher.

Historicamente, as desigualdades foram superadas por mudanças axiológicas de cunho moral, impondo mudanças de paradigmas. Por isso, Tom Regan propõe para a discussão, em oposição ao positivismo, e, consequentemente, ao especismo, trabalhar os direitos morais. Os direitos morais com o aspecto de universalidade, partindo da premissa que todos tem esse direito e que devem ser respeitados por todos. Propõe, também, os direitos morais como instrumento de igualdade entre os indivíduos, onde todos possuem o mesmo direito e não graus diferenciados e, por fim, que os direitos morais nascem com o indivíduo (Regan, 2004).

Para Regan (2004, p. 267)

[...] o direito de ser respeitado deve ser entendido como tema principal, já que sintetiza a regra de ouro da ética que impõe que todos sejam tratados igualmente, independentemente das muitas diferenças.

Essa paridade de tratamento proposto pelo filósofo propõe uma mesma ideia de dignidade entre o humano e não humano, abstraindo o conceito de pessoa, para encampar a definição de sujeitos-de-uma-vida, onde todos são iguais por serem "um alguém", "um fim" (Silva, 2012).

Segundo Anamaria Feijó (2008, p. 142)

Para que a dignidade seja possível de ser dada a outros seres vivos precisa ser conceituada de forma subjetiva, sendo ampliada através da aceitação do binômio dignidade/respeito. Dizendo que algo é digno de respeito estaremos outorgando dignidade àquilo que merece ser respeitado. $\mathrm{O}$ conceito subjetivo de dignidade pode assim ser atrelado ao animal nãohumano, entendendo-o como participe da biosfera, como ser passível de respeito pelo papel que exerce nesse sistema global devendo ser sua integridade respeitada e defendida. 
A Declaração Universal dos Direitos dos Homens, em 1948 através da Organização das Nações Unidas aprovou, em seu artigo primeiro que: Todos homens nascem livres eiguais em dignidade e direito.

Esse conceito de dignidade vem paulatinamente sendo estendido, fruto do reconhecimento pela ciência da inter-relação do homem com todo o universo e seres neles existentes. Essa materialização, ainda que soft law, é avistável na Declaração Universal dos Direitos do Animal, datada de 1978. Consta em seu artigo segundo que: "Todos os animais nascem iguais diante da vida e tem o mesmo direito à existência".

E em seu artigo quarto ela reconhece que: [...] cada animal pertencente à espécie selvagem tem o direito de viver livre no seu meio natural terrestre, aéreo ou aquático e tem o direito de reproduzir-se.

A Declaração dos Direitos do Animal traz consigo uma proposta de uma nova ética biológica, uma postura de vida e de respeito aos animais numa valoração intrínseca, que permite dizer que o mesmo também é sujeito de direitos.

Avançando um pouco mais no reconhecimento da dignidade do não-humano e, consequentemente na condição de sujeito de direito, agora sob o prisma positivista propriamente dito, ilustro o debate com a Constituição do Equador, de 2008, que de forma pioneira no mundo, fez constar a natureza como sujeito de direitos.

Estabelece o art. 71, que

\footnotetext{
Natureza ou Pachamama, onde se reproduz e realiza vida, tem o direito de integral respeito a sua existência e manutenção e regeneração de seus ciclos vitais, estrutura, funções e processos evolutivos.

Toda pessoa, comunidade, cidade ou nacionalidade pode exigir o cumprimento autoridade pública com as leis da natureza. Para aplicar e interpretar esses direitos foram observados os princípiosestabelecido na Constituição, conforme o caso.O Estado vai encorajar as pessoas singulares e coletivas, a grupos para proteger a natureza e promover o respeito para todosos elementos que formam um ecossistema.
}

Avançando um pouco mais discussão proposta, não se pode restringir adjetivo dignidade como algo próprio e exclusivo do humano, mas de todas as formas de manifestações (Silva, 2009).

Por tal razão criticasse a ética tradicional condicionado ao outro, no relacionamento do homem com o homem, traços de uma ética antropocêntrica. Pois, a relação do homem com a natureza não deve ser de ética utilitária, mas do reconhecimento de uma dignidade a ser alcançada em substituição aos imperativos éticos homocêntrico (Jonas, 1995). 
Deve-se pensar o direito numa perspectiva de se incluir o animal não-humano como sujeito de direito numa visão de responsabilidade solidária, na visão de Jürgen Habermas do outro como um dos nossos, propiciando um patamar mínimo de justiça social.

A Constituição Federal prever em seu art. 225 essa ideia mínima de justiça social, quando vedou qualquer espécie de submissão do animal a tratamento cruel. Para parte de doutrina, o texto acima citado retrata a mudança de paradigma jurídico-constitucional socioambiental com a formação de uma dimensão ecológica da dignidade humana (Silva, 2009).

O tratamento dado pela constituição pátria ao animal não-humano e tantas outra já citadas, permite concluir pela existência de um direito animal constitucional e, por via de consequência, numa nova concepção de dignidade que transcende o humano para alcançar também o não-humano.

Assim, vê-se que até o direito positivado está rendendo-se a ideia de dignidade ao animal não humano, conferindo-lhe o status de sujeito de direito.

É fato que se precisa avançar, mas jamais retroceder, como alerta Tagore Trajano, quando se reportou ao princípio da teoria da proibição do retrocesso em seu ensaio sobre os Fundamentos do direito animal constitucional, para não admitir uma afronta a dignidade do animal pelas legislações infraconstitucionais frente aos avanços de uma tutela mínima obtida em sede constitucional.

\section{CONSIDERAÇÕES FINAIS}

A proteção ao meio ambiente tem pautado uma série de discussões em todo mundo, tendo em vista a ação exploratória ao longo da história da humanidade. Hoje, em decorrência do passado devassador do homem, percebe-se a necessidade de preservação deste meio ambiente com um olhar não só para o presente, mas também para as gerações futuras.

Nesta concepção protetiva, passou-se a discutir a proteção dos animais, mormente, dentro desse contexto de meio ambiente, sob um prisma de dignidade, para conferir-lhes a condição de sujeito de direitos e não de proteção da natureza sob o viés utilitarista.

Assim, do presente ensaio, que se propôs fazer uma abordagem filosófica da não aceitação do animal não humano como sujeito de direitos, é possível expressar algumas conclusões que traduzem as ideias aqui desenvolvidas.

1. O pensamento antropocêntrico, fundado nas ideias aristotélicas, de Descartes e Kant, contrapõe-se ao reconhecimento moral de igualdade material entre o humano e não- 
humano, por entenderem que os animais não são um fim em si mesmo, mas meio de satisfação do animal homem.

2. Esse antropocentrismo sustenta que o não-humano não possui dignidade, pois tal é sentimento intrínseco da condição humana, em razão de ser o único, dentre todos os seres dotados da capacidade de pensar e agir de acordo com o pensamento, característico de um espírito narcisista.

3. O narcisismo do animal racional vem, paulatinamente decaindo, pois a espécie humana não é diferente do não-humano na seara dos direitos morais, pois são todos semelhantes.

4. A visão homocêntrica não mais subsiste dentro desse novo contexto filosófico que envolve o humano e não humanos, notadamente pela contribuição proposta a humanidade por Darwin, Peter Singer e Tom Regan. O animal não humano possui dignidade, valor intrínseco e, portanto, pode ser sujeito de direitos.

5. No plano constitucional tem se verificado essa proteção mínima em várias constituições, freando a exploração do homem em detrimento do animal, partindo da premissa de direitos mínimos já concebidos.

\section{REFERÊNCIAS}

ARISTÓTELES. Ética a Nicômaco. Trad. Pietro Nassetti. São Paulo: Martin Claret Ltda., 2007.

BARLETT, Steven J. Raízes da resistência humana aos direitos dos animais: Bloqueios psicológicos e conceituais. Revista Brasileira de Direito Animal. Ano 2. Número 3. Jul/Dez 2007.

BOSSELMANN, Klaus. .Environmental Rights and Duties: the concept of ecologicalhuman rights..Artigo apresentado no $10^{\circ}$ Congresso Internacional de Direito Ambiental,em São Paulo, 5 8 de junho de 2006.

Constituição

Federal:

BRASIL. Constituição (1988). Constituição da República Federativa do Brasil. Brasília, DF: Senado, 1988. Acesso: 07 de setembro de 2016.

Declaração Universal dos Direitos Dos Animais, https://www.suipa.org.br/index.asp?pg=leis.asp. Acesso: 07 de set. de 2016. 
Declaração Universal dos Direitos Homens, http://unesdoc.unesco.org/images/0013/001394/139423por.pdf. Acesso: 07 de set. de 2016.

DESCARTES, René. Discurso do método. Trad. J. Guinsburg e Bento Prado Júnior. São Paulo: Nova Cultural, 1996.

FEIJÓ, Anamaria. A dignidade e o animal não-humano. In MOLINARO, Carlos Alberto et al (org.).A dignidade da vida e os direitos fundamentais para além dos humanos: uma discussão necessária. Belo Horizonte: Fórum, 2008.

FENSTERSEIFER, Tiago. Direitos fundamentais e proteção do ambiente: a dimensão ecológica da dignidade humano no marco jurídico-constitucional do Estado Socioambiental de Direito. Porto Alegre: Livraria do Advogado Editora, 2008.

JONAS, Hans. El principio de responsabilidad: ensayo de una ética para la civilización tecnológica. Barcelona: Herder, 1995

KANT, Immanuel. Fundamentação da metafísica dos costumes. Trad. A. Pinto de carvalho. São Paulo. Editora Nacional. 1964

REGAN, Tom. Jaulas vazias: encarando o desafio dos direitos animais. Tradução: Regina Rheda. São Paulo: Lugano, 2006.

REGAN, Tom. The case of animal right. $2^{\mathrm{a}}$ ed. California: University of Califonia Press, 2004.

SARLET, Ingo Wolfgang. Dignidade da pessoa humana e direitos fundamentais naConstituição Federal de 1988. 4. ed. Porto Alegre: Livraria do Advogado, 2006.

SILVA, Tagore Trajano de Almeida. Animais em Juízo: direito, personalidade jurídica e capacidade processual. Salvador: Evolução, 2012.

SILVA, Tagore Trajano de Almeida. Direito Animal e Hermenêutica Jurídica da Mudança: Animais como novos sujeitos de direito. Trabalho publicado nos Anais do XVIII Congresso Nacional do CONPEDI, realizado em São Paulo - SP nos dias 04, 05, 06 e 07 de novembro de 2009

SINGER, Peter. Libertação animal. Trad. Marly Winckler. Lugano: São Paulo: editora, 2004.

V. Steven J. Bartlett, Narcissism and Philosophy, 19 Methodology \& Sci. 16, 17 (1986) 
VENEZUELA. Constitución de la República Bolivariana de Venezuela. Diário Oficial, n. 36.680, 30 dez. $1999 . \quad$ Disponível em:

http://www.asambleanacional.gov.ec/documentos/constitucion_de_bolsillo.pdf>. Acesso em: 06 de jul. de 2016

http://extra.globo.com/noticias/mundo/cacadora-de-12-anos-se-defende-das-criticas-apos-posarcom-animais-mortos-20052822.html - <acessado em 05/09/2016>

http://portal.tjsc.jus.br/web/sala-de-imprensa/-/juiz-entende-que-cao-nao-e-objeto-e-remetedisputa-por-animal-para-vara-de-familia> acessado em 05 de setembro de 2016. 